\title{
Popular support for progressive taxation
}

\author{
Francisco Marhuenda, Ignacio Ortuño-Ortín* \\ Dept. Fundamentos Análisis Económico, University of Alicante, Alicante, Spain
}

Received 24 June 1994; accepted 12 July 1994

\begin{abstract}
The popular support obtained by two parties who propose two qualitatively different tax schemes is analyzed. We show that if the median voter is below the mean, then any progressive proposal wins over a regressive one.

Keywords: Voting; Income tax; Progressiveness

JEL classification: $\mathrm{D} 72$
\end{abstract}

\section{Introduction}

Income tax schedules in most developed democratic countries are such that the average and the marginal tax rate are increasing with income (Snyder and Kramer, 1988). One possible explanation for the prevalence of this type of tax schedule is that the central authority designs it trying to maximize some utilitarian social welfare function.

An alternative approach is to consider the tax policies adopted in a democratic society as the outcome of a voting mechanism. In this case it is usually assumed that political parties propose different tax schemes, and agents, who are self-interested, vote for their most preferred one. This approach might be seen as unrealistic since in actual societies this kind of process rarely takes place. However, as Roberts (1977) notes, "the point is not whether choices in the public domain are made through a voting mechanism but whether choice procedures mirror some voting mechanism".

The literature on this area is still very inconclusive on the connection between progressive taxation and voting. Foley (1967), Romer (1975, 1977), and Roberts (1977) analyze the outcome of a majority-rule voting scheme in which the proposed tax policies must be linear

\footnotetext{
We thank S. Chattopadhyay and L. Corchón for their comments. Financial support from I.V.I.E. and from the Ministry of Education projects no. PS 90-0156 and PB 91-0756 is gratefully acknowledged.

${ }^{*}$ Corresponding author.
} 
functions of income. Snyder and Kramer (1988) study the existence of progressiveness of income taxation as a voting equilibrium in an economy with two sectors "a legal, taxable sector, and an underground, untaxable sector". But they only admit tax functions which are individually optimal for some voter. Cukierman and Meltzer (1991) analyze a model in which the tax functions are quadratic in income. They provide some sufficient conditions for the median voter's most preferred tax function to be a Condorcet winner. They also show that under additional, rather strong conditions, such a tax function is progressive. Roemer (1993) provides simulated equilibria in a model with constituency-representing parties and uncertainty. But the admissible tax functions are also quadratic in income.

In this paper we consider a model in which income levels are fixed - so incentive problems are left aside. The set of admissible tax schemes contains all the non-decreasing concave and convex functions (including linear functions) on income that raise just enough revenue to meet an exogenously given revenue target. We do not try, however, to characterize which $\operatorname{tax}$ scheme is the equilibrium outcome of a voting mechanism. The reason for this is that it is well known that unless we assume very strong restrictions on the admissible tax schemes - as the above-mentioned authors do - majority rule will not lead to a Condorcet winner (see, for example, Bucovetsky, 1991). The goal here is just to establish some general conclusions about the popular support for progressive tax schemes versus regressive ones. Our main result is that, for income distributions with a median below the mean, any concave tax scheme obtains less popular support than any convex tax scheme provided that this one treats the poorest agent no worse than the concave tax scheme. Even though we do not provide a complete positive model of progressive taxation - such a model cannot consist of just a majority rule mechanism and it should contain more realistic elements as, for example, uncertainty, ideological parties, voting on multidimensional issues, multiparty elections, etc. - our result may help to understand why most democracies have increasing average and marginal tax rates.

\section{The model}

The economy consists of a large number of agents who differ in their income. The income distribution is fixed and is described by a non-atomic measure $\alpha$ on the interval $[0,1]$. We identify an agent with its income $x \in[0,1]$.

We consider two political parties represented by $i \in\{1,2\}$ who propose two different income tax policies, $t_{1}$ and $t_{2}$, designed to collect a given amount of revenue $R$ from the taxpayers. Both political parties know the income distribution $\alpha$ and their objective is to win the election.

Assumption 2.1. The tax policy put forward by each party must satisfy the following requirements.

(1) For each $x \in[0,1], t(x) \leqslant x$.

(2) The tax policy $t(x)$ is continuous and non-decreasing in $x$.

(3) $\int_{0}^{1} t(x) \mathrm{d} \alpha=R$. 
(4) $R<\int_{0}^{1} x \mathrm{~d} \alpha$.

Condition (1) says that tax liabilities cannot exceed income. Observe that we do not require $t(x) \geqslant 0$ allowing, therefore, for possible redistribution of income. The second requirement seems a very natural restriction. Note that we do not require $t$ to be differentiable at all points. Condition (3) requires that the total tax collected must meet the target $R$. Condition (4) means that $R$ is feasible.

Given the two proposals, $t_{i}, i \in\{1,2\}$, made by the parties, agent $x$ will vote for the one which minimizes his tax payment. Thus given $t_{1}$ and $t_{2}$, the voting is given by the function $\varphi_{t_{1}, t_{2}}:[0,1] \rightarrow\{1,2\}:$

$$
\varphi_{t_{1}, t_{2}}(x)= \begin{cases}1, & \text { if } t_{1}(x)<t_{2}(x) \\ 2, & \text { if } t_{1}(x) \geqslant t_{2}(x)\end{cases}
$$

For simplicity we have assumed that if an agent is indifferent between the two alternatives $t_{1}$ and $t_{2}$, he will vote for $t_{2}$. In our model this will play no role since the set of indifferent agents will have measure zero. Given $\varphi_{t_{1}, t_{2}}$ the votes obtained by party 1 is

$$
N\left(t_{1}, t_{2}\right)=\alpha\left(\varphi_{t_{1}, t_{2}}^{-1}(1)\right) .
$$

Party 1 wins the election if $N\left(t_{1}, t_{2}\right)>1 / 2$ and loses it if $N\left(t_{1}, t_{2}\right)<1 / 2$. Whenever $N\left(t_{1}, t_{2}\right)=$ $1 / 2$, party 1 wins with probability $1 / 2$. Again, in Proposition 2.4 below, this last possibility will not be relevant. The implemented tax policy will be the one proposed by the winning party.

Definition 2.2. The median voter is the agent with income $x_{\mathrm{M}}$ such that

$$
\int_{0}^{x_{M}} \mathrm{~d} \alpha=\frac{1}{2}
$$

We denote the mean income by $\mu$.

Definition 2.3. Given two proposals for tax policies, $t_{1}$ and $t_{2}$, we will say that policy $t_{1}$ is progressive and $t_{2}$ is regressive if $t_{1}(0) \leqslant t_{2}(0)$ and $t_{1}$ is convex and $t_{2}$ is concave.

Proposition 2.4. Suppose $x_{\mathrm{M}}<\mu$ and let $t_{1} \neq t_{2}$ two tax policies with $t_{1}$ progressive, $t_{2}$ regressive and both satisfying Assumption 2.1. Then $N\left(t_{1}, t_{2}\right)>1 / 2$.

Proof. Let $t_{1}$ be progressive and $t_{2}$ regressive. Since $t_{1} \neq t_{2}$, they must intersect at exactly one point $\theta>0$. Clearly all agents $x \in(0, \theta)$ prefer $t_{1}(x)$ rather than $t_{2}(x)$, i.e. $t_{1}(x)<t_{2}(x)$ for $x \in(0, \theta)$.

Consider the lines $p(x)=a x+b$ [resp. $r(x)=c x+d]$ such that $p(\theta)=t_{1}(\theta)$ [resp. $r(\theta)=$ $t_{2}(\theta)$ ] and $p(x)$ is below the graph of $t_{1}(x)$ [resp. $r(x)$ is above the graph of $t_{2}(x)$ ] (see Fig. 1). If $t_{1}^{\prime}(\theta)$ exists, then $a=t_{1}^{\prime}(\theta)$. Otherwise, $a \in\left[t_{1}^{\prime}(\theta-), t_{1}^{\prime}(\theta+)\right]$. And similarly for $r(x)$. We remark that we may take $a>c$, because $t_{1}$ is convex and $t_{2}$ is concave. 


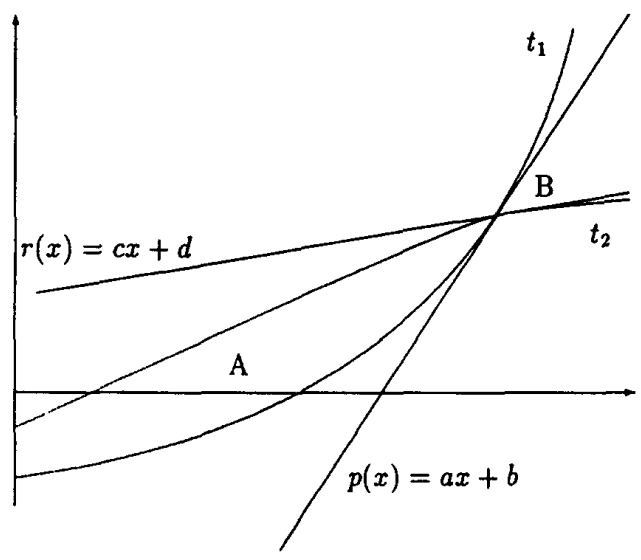

Fig. 1.

Since $t_{1}$ and $t_{2}$ collect the same tax, then

$$
R=\int_{0}^{\theta} t_{1} \mathrm{~d} \alpha+\int_{\theta}^{1} t_{1} \mathrm{~d} \alpha=\int_{0}^{\theta} t_{2} \mathrm{~d} \alpha+\int_{\theta}^{1} t_{2} \mathrm{~d} \alpha
$$

i.e.

$$
A=\int_{0}^{\theta}\left(t_{2}-t_{1}\right) \mathrm{d} \alpha=\int_{\theta}^{1}\left(t_{1}-t_{2}\right) \mathrm{d} \alpha=B .
$$

Let

$$
C=\int_{0}^{\theta}(r(x)-p(x)) \mathrm{d} \alpha, \quad D=\int_{\theta}^{1}(p(x)-r(x)) \mathrm{d} \alpha .
$$

Observe that all these quantities are positive and $C \geqslant A=B \geqslant D$, with at least one inequality strict, since $t_{1} \neq t_{2}$. Hence,

$$
\int_{0}^{\theta}(r(x)-p(x)) \mathrm{d} \alpha>\int_{\theta}^{1}(p(x)-r(x)) \mathrm{d} \alpha,
$$

which is the same as

$$
\int_{0}^{1}(p(x)-r(x)) \mathrm{d} \alpha<0,
$$

i.e.

$$
(a-c) \mu=(a-c) \int_{0}^{1} x \mathrm{~d} \alpha<(d-b) \int_{0}^{1} \mathrm{~d} \alpha=d-b .
$$


But, since $p$ and $r$ intersect at $\theta$ we have that $a \theta+b=c \theta+d$, so $(a-c) \theta=d-b$. By hypothesis, $x_{\mathrm{M}}<\mu$ so that

$$
(a-c) \theta=d-b>(a-c) \mu>(a-c) x_{\mathrm{M}} .
$$

We conclude, hence, that $\theta>x_{\mathrm{M}}$, which finishes the proof.

In the case when redistribution of income is not allowed, then one obtains the following result.

Corollary 2.5. Suppose (1) in Assumption 2.1 is strengthened to:

for each $x \in[0,1], 0 \leqslant t(x) \leqslant x$.

Then any convex tax policy wins over any concave one.

\section{Conclusion}

There is not yet a widely accepted theory of income redistribution and democracy. A possible explanation for this is that most elections are on multi-issue policies. Hence, just the redistributional aspects of the proposals made by the parties are not enough to explain the way agents vote.

Consequently, our model does not attempt to provide a complete theory of voting and redistribution. Proposition 2.4 shows only some qualitative ideas of the relative support a progressive tax scheme, as compared with a regressive one, would obtain.

The following question seems quite natural now in this set up: Are there any circumstances under which a concave tax policy can beat a convex one? The answer, as explained in Fig. 2 , is affirmative, provided the poorest segment of people is better off with the concave tax scheme.

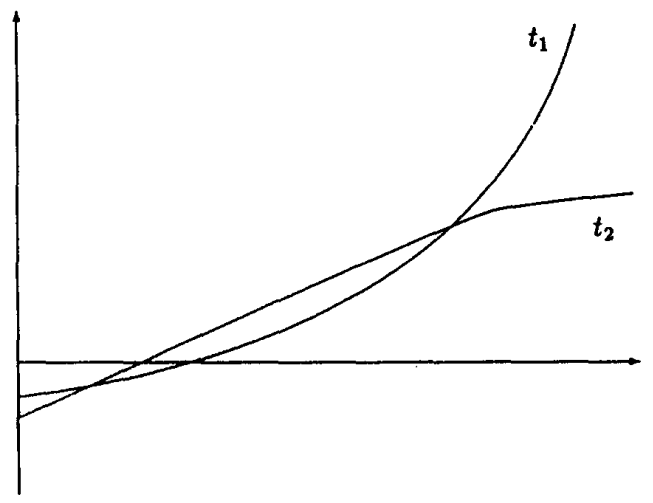

Fig. 2. 
That is, a party proposing a concave tax policy which favors the very poor can win an election when confronted with a convex tax plan.

\section{References}

Bucovetsky, S., 1991, Choosing tax rates and public expenditure levels using majority rule, Journal of Public Economics 46, 113-131.

Cukierman, A. and A.H. Meltzer, 1991, A political theory of progressive income taxation, in: A. Meltzer, A. Cukierman and S.F. Richard, Political economy (Oxford University Press, New York) ch. 5.

Foley, D., 1967, Resource allocation and the public sector, Yale Economic Essays 7, 45-98.

Roberts, K., 1977, Voting over income tax schedules, Journal of Public Economics 8, 329-340.

Roemer, J., 1993, The political economy of progressive taxation in a two party system, mimeo.

Romer, T., 1975, Individual welfare, majority voting, and the properties of a linear income tax, Journal of Public Economics, 4, 163-185.

Romer, T., 1977, Majority voting on tax parameters, Journal of Public Economics 7, 127-133.

Snyder, J.M. and G.H. Kramer, 1988, Fairness, self-interest, and the politics of the progressive income tax, Journal of Public Economics 36, 197-230. 